\title{
Research on the Carbonization Process of Potassium Chloride Solutions in the Presence of Diethylamine
}

\author{
Bobokulov Akbar Nosirovich, Erkaev Aktam Ulashevich, Kucharov Bakhrom Khayrievich, \\ Toirov Zakir Kalandarovich
}

\begin{abstract}
BACKGROUND: Currently in the country there is no production of potassium carbonates, which, as a rule, they are purchased in the CIS countries. At the same time, there has explored sufficient reserves of potassium-containing raw materials, which, according to technological, economic and, most importantly, rational utilization levels, will provide an opportunity to get their own potassium carbonate to ensure internal and external consumption markets.

In this regard, the development of a method of producing potash based on local raw materials is currently actual.

RESULTS: The process of obtaining potassium bicarbonate by the amine method has been studied for the first time. The optimal process parameters were established: $\triangle P=2 \mathrm{~atm}$, duration -45 min.

CONCLUSION: The study found that the resulting potassium bicarbonate precipitates quickly from the suspension and is easily filtered, which allows us to recommend the use of existing standard thickeners and filtering plants with a minimum working surface.
\end{abstract}

Keywords: potassium bicarbonate, potassium chloride, amine, carbonization, method.

\section{INTRODUCTION}

Prospects for the use of potassium carbonates, in particular, as chlorine-free potassium mineral fertilizers, create certain conditions for the organization of their production in the country. There is currently no production of potassium carbonates, which, as a rule, they are purchased in the CIS countries. At the same time, there has proven reserves of potassium-containing raw materials, which, according to technological, economic and, most importantly, rational utilization levels, will provide an opportunity to get their own potassium carbonate to provide domestic and foreign consumption markets ${ }^{1-2}$.

All existing industrial methods for the production of potassium carbonate can be divided into two groups. The first group of schemes is based on the production of potassium bicarbonate (KHCO3), similar to the ammonia method of producing soda by carbonization of potassium chloride (KC1) in the presence of various aliphatic amines and their salts ${ }^{4-5}$.

Potash is used in the manufacture of glass, from highgrade grades of which medical, optical, electro vacuum, art glass, and also crystal. Potash is employed for the synthesis of certain salts, liquid potassium salt, synthetic detergents, in

\footnotetext{
Revised Manuscript Received on July 18, 2019.

Bobokulov Akbar Nosirovich, Tashkent chemical-technological institute, 32, Navoi Str., Tashkent, Uzbekistan

Erkaev Aktam Ulashevich, Tashkent chemical-technological institute, 32, Navoi Str., Tashkent, Uzbekistan

Kucharov Bakhrom Khayrievich, Tashkent chemical-technological institute, 32, Navoi Str., Tashkent, Uzbekistan

Toirov Zakir Kalandarovich, Tashkent chemical-technological institute, 32, Navoi Str., Tashkent, Uzbekistan
}

the preparation of liquid and solid carbon dioxide, in construction and agriculture. Despite the presence of potassium chloride deposits, potash production is absent.

In this work, we studied the possibility of an amine method for obtaining potash from local raw materials potassium chloride, produced at the UE "Dekhkanabad Potash Fertilizer Plant" (UE "DPFP"), and carbon dioxide, which is waste of nitrogenous production.

This method of obtaining potash is based on the carbonization under pressure of a solution of potassium chloride in the presence of diethylamine $\mathrm{NH}(\mathrm{R})_{2}$.

$\mathrm{KCl}+\mathrm{NH}(\mathrm{R})_{2}+\mathrm{CO}_{2}+\mathrm{H}_{2} \mathrm{O}=\mathrm{KHCO}_{3}+\mathrm{NH}(\mathrm{R})_{2} * \mathrm{HCl}$

When it is cooled, crystalline $\mathrm{KHCO}_{3}$ precipitates and it is easily separated from diethylamine hydrochloride solution. The latter is again converted to free diethylamine by the reaction.

$$
\mathrm{NH}(\mathrm{R})_{2} * \mathrm{HC}_{1}+\mathrm{Ca}(\mathrm{OH})_{2}=\mathrm{NH}(\mathrm{R})_{2}+\mathrm{CaCl}_{2}+2 \mathrm{H}_{2} \mathrm{O}
$$

\section{CARBONIZATION PROCESS OF POTASSIUM CHLORIDE SOLUTIONS IN THE PRESENCE OF DIETHYLAMINE}

The experiments were carried out in a laboratory setting consisting of a cylindrical metal reactor with a heatexchange jacket, equipped with a barbater and temperature and pressure sensors in the reaction zone. The starting material used was potassium chloride UE DPFP, reactive DEA, carbon dioxide and water. In the experiments, the calculated amount of potassium chloride, diethylamine (DEA) and water was fed into the carbonization reactor and carbon dioxide was passed in for 5-40 minutes at a given pressure. The kinetics of temperature change in the reaction mass was fixed by thermometer.

\section{METHODOLOGY}

The experiments were carried out in a laboratory setting consisting of a cylindrical metal reactor with a heatexchange jacket, equipped with a barbater and temperature and pressure sensors in the reaction zone. The starting material used was potassium chloride Ltd. DPP, reactive DEA, carbon dioxide and water. In the experiments, the calculated amount of potassium chloride, diethylamine (DEA) and water was fed into the carbonization reactor and carbon dioxide was passed in for 5-40 minutes at a given pressure. The kinetics of temperature change in the reaction mass was fixed by thermometer.

Published By:

Blue Eyes Intelligence Engineering 


\section{RESEARCH ON THE CARBONIZATION PROCESS OF POTASSIUM CHLORIDE SOLUTIONS IN THE PRESENCE OF DIETHYLAMINE}

The samples visualization was conducted on a microscope (Leica, Germany) controlling with computer. The optical system of the Leica DM500 microscope includes a lens, an eyepiece and a lighting device - a condenser with a diaphragm with a light filter and an electric illuminator. A Leica DM500 optical binocular microscope gives an increase in the range of 4 to 100 times. The magnifications of the lens are indicated by numbers on the handle $-\mathrm{x} 4, \mathrm{x} 10, \mathrm{x} 40, \mathrm{x} 100$.

The thermal stability of the studied crystal samples was determined on a Netzsch Simultaneous Analyzer STA 409 PG instrument, with a K-type thermocouple (Low RG Silver) and aluminum crucibles. All measurements were carried out in an inert nitrogen atmosphere with a nitrogen flow rate of $50 \mathrm{ml} \mathrm{/} \mathrm{min}$. The temperature range of measurements was $25-400{ }^{\circ} \mathrm{C}$, the heating rate was $5 \mathrm{~K} /$ $\mathrm{min}$. The amount of sample per measurement is 5-6 mg. The measuring system was calibrated with a standard set of substances KNO3, In, Bi, Sn, Zn, CsCl.

Samples were identified on the basis of diffraction pattern, which were recorded on a XRD-6100 apparatus (Shimadzu, Japan), controlling with computer. CuK $\alpha$ radiation ( $\beta$-filter, $\mathrm{Ni}, 1.54178$ mode of the tube current and voltage $30 \mathrm{~mA}, 30 \mathrm{kV}$ ) and a constant rotational speed of the detector of $4 \mathrm{deg} / \mathrm{min}$ with a step of $0.02 \mathrm{deg}$ were used. ( $\omega / 2 \theta$-clutch), and the scanning angle was changed from 4 to $80 \mathrm{o}$.

\section{RESULTS AND DISCUSSION}

The separation of potassium bicarbonate crystals was carried out by decantation with further filtration of the thickened part and the initial suspension. The chemical composition of potassium bicarbonate and the filtrate was determined by chemical analysis methods. The yield of potassium bicarbonate was calculated and the changes in $\mathrm{pH}$ and density of the liquid phase were determined depending on the value of the technological parameters.

From the data in the Table 1 it is seen that with an increase in the DEA rate from 53 to $147 \%$, the $\mathrm{pH}$ of the reaction mass increases from 8.35 to 9.31 . Increasing the pressure at the same rates of DEA also leads to an increase in $\mathrm{pH}$, for example, with an increase in pressure from 0.5 to $2 \mathrm{kgf} / \mathrm{cm} 2$, the $\mathrm{pH}$ of the reaction mass increases from $9.04 ; 9.14 ; 9.21$ to $9.14 ; 9.25 ; 9.31$, respectively, at the rate of DEA 100, 133, 147\%. The density of the liquid phase has the same dependence on technological parameters and varies in the intervals of 1.044-1.085 $\mathrm{g} / \mathrm{cm} 3$.

It can be seen in the table and figure. 1 that the yield of potassium bicarbonate is clearly influenced by the rate of DEA and the carbon dioxide supply pressure. At $100 \%$ DEA rate, an increase in $\mathrm{CO} 2$ pressure up to $3 \mathrm{kgf} / \mathrm{cm} 2$ practically does not affect the yield of KHCO3, and its further increase to $4 \mathrm{kgf} / \mathrm{cm} 2$ reduces the output of potassium bicarbonate from $69.0 \%$ (at $2 \mathrm{kgf} / \mathrm{cm} 2$ ) to 64 , $46 \%$. This is due to the increase in the degree and blowing of the DEA from the gas phase. Increasing the DEA rate to $133 \%$ provides an increase in the yield of $\mathrm{KHCO} 3$ as compared with the $100 \%$ DEA rate, especially at pressures above $2 \mathrm{kgf} / \mathrm{cm} 2$ (Figure. 1, curve 2).

$<$ Figure 1 near here $>$

$<$ Table 1 near here >

A further increase in the rate of DEA to $147 \%$ slightly increases the yield of bicarbonate. For example, at a pressure of $\mathrm{CO} 2$ of $2 \mathrm{kgf} / \mathrm{cm} 2$, the rate of DEA from 100 to $133 \%$, the yield of KHCO3 increases by $14.4 \%$. A further increase in the norm to $147 \%$ increases the product yield by only $2.64 \%$. In the figure, the $\mathrm{AB}$ line shows the optimal $\mathrm{CO} 2$ pressure, which ensures the maximum yield of potassium bicarbonate at the given DEA norms.

From Fig. 2 (a) it is seen that with an increase in the DEA rate, the yield of potassium bicarbonate passes through a maximum at a rate of $148 \%$, and its further increase leads to a decrease in product yield.

$<$ Figure 2 (a) near here >

From Fig. 2 (b) it can be seen that at $\Delta \mathrm{P}-2$ atm and a rate of $147 \%$ within $8-9$ minutes, the yield reaches more than $63 \%$ and a further increase in the duration to 24 and 40 minutes increases the degree of yield by 15 and $8 \%$, respectively. It is necessary to take into account that with an increase in the duration of the process losses $\mathrm{CO} 2$ increase proportionally.

$<$ Figure 2 (b) near here >

At the optimizing of the parameters of the technology for producing potassium bicarbonate, the process of separating is of no small importance in the resulting product from the carbonized suspension, which was studied by decanting and filtering (Figure 3.4 and Table 2).

$<$ Figures 3,4 near here >

$<$ Table 2 near here $>$

Decantation was carried out in a $500 \mathrm{ml}$ measuring cylinder with visual observation of the kinetics of changes in the transparent part.

At a DEA rate of $57 \%$ for 60 seconds, the degree of clarification of the suspension reaches to $51 \%$, the maximum of which $65 \%$ is reached after 120 minutes and then the precipitation process ends in practice (Figure. 3 ).

< Figure 3 near here >

With an increase in the DEA rate to $100 \%$ or more compared to the $57 \%$ rate, the degree of precipitation sharply decreases from 65 to $20-22 \%$ with the same duration of settling. The maximum degree of deposition reaches $43.45,37.3$ and $41.17 \%$, respectively, with the norms of 100, 133 and 147\% DEA for 300 seconds.

In Figure 3, the kinetic curve of the dependence of the degree of deposition consists of a straight and curvilinear segment, which is explained by the course of the process in two stages. In the first stage, free crystallization occurs with overcoming the resistance of only the liquid phase, which explains the constant deposition rate. The second stage is characterized by overcoming the additional resistance of the layer, which increases over time, which causes a decrease in the deposition rate until the advancement of the upper layer of sediment stops.

The duration of the transition of the first stage to the second is limited by the line $A B$, which shows that with an increase in the DEA rate, the duration of the first stage increases from 60 to 300 seconds simultaneously with a decrease in the deposition rate from 51 to $37.3 \%$ (Figure 3). 


\section{< Figure 3 near here >}

Isochrones were conducted at $30 ; 60 ; 120$ and $240 \mathrm{sec}$ for a more accurate elucidation of the influence of the DEA rates on the settling stage (Fig.4), which showed that the dependence on the norms for the degree of deposition has a complex wave-like dependence.

< Figure 4 near here >

A wide practically stable zone of minimum isochrone is observed in the intervals of the DEA rate of $100-150 \%$. With an increase in the duration of settling, the wave-like change in the isochrone gradually levels off and after 300 seconds, curve 5 passes into a smooth curve in practice with shallow minima of the corresponding DEA-100-150\% rates.

The table shows that with an increase in the rate of DEA from 100 to $147 \%$, the filtration rate of the suspension by the solid and by the liquid phase increases from 417.3; 921.97 and $1290.04 ; 2789.4$ to $8950.8 ; 2867.17$ and $3098.92 ; 7462.34 \mathrm{~kg} / \mathrm{m} 2 * \mathrm{~h}$, respectively, at a carbon dioxide pressure of 0.5 and $2.0 \mathrm{kgf} / \mathrm{sm} 2$.

The resulting graph based on thermal analysis will show that on the curve of digestion of the obtained sample of Fig. 5 , two endothermic peaks are observed. The first Tmax = $125.80 \mathrm{C}$ corresponds to the melting of the sample, the second $\mathrm{Tmax}=181.6 \mathrm{oC}-$ to the decomposition of the sample with a maximum rate of $5 \% / \mathrm{min}$. The total mass loss during decomposition is $29 \%$. The total activation energy is $\Delta \mathrm{Q}=-703.4 \mathrm{~J} / \mathrm{g}$.

The resulting potassium bicarbonate is identified by $\mathrm{X}$ ray and microscopic methods. According to the X-ray analysis of Fig. 6, that the obtained sample (Table 2, experiment 8, Figures 5,6) contain potassium bicarbonate and potassium chloride; which correspond to characteristic peaks; KHCO3 - 2.953, 2.846, 2.614 and $\mathrm{KCl}-3.125$, 2.214 .

< Figures 5,6 near here >

$<$ Table 2 near here >

As shown by X-ray analysis of the samples with a single sprinkling with growth of potassium bicarbonate with a ratio of $\mathrm{L}: \mathrm{S} 1 \div 1$, the residual potassium chloride is 5.05 . It is recommended to increase $\mathrm{L}: \mathrm{S}$ more than 1.5 .

\section{CONCLUSION}

Thus, on the basis of the foregoing, the optimal conditions for obtaining potassium bicarbonate are the rate of DEA $-140 \%$, the pressure in the reaction zone is $2.3-3.1$ $\mathrm{kgf} / \mathrm{cm} 2$, the process takes 25 minutes with a product yield of more than $86 \%$.

It was also found that the resulting potassium bicarbonate precipitates quickly from the suspension and is easily filtered, which allows us to recommend the use of existing standard thickeners and filtering plants with a minimum working surface. The influence of the DEA rates, the pressure of carbon dioxide and the duration of the carbonization process of a mixture of solutions of potassium chloride and DEA was studied. The optimal technological parameters were established: $\Delta \mathrm{P}-2$ atm, the norm - $140 \%$, the process duration - 25 minutes. The degree of output of potassium bicarbonate reaches to more than $86 \%$.

\section{LIST OF CAPTIONS}

Figure 1. The change in the degree of yield of potassium bicarbonate depending on the pressure of carbon dioxide and the norm of DEA. Norm DEA, \%: 1-100, 2-133, 3-147.

Figure $2(a, b)$. Change in the degree of potassium bicarbonate yield depending on the carbon dioxide pressure (a) and the process duration (b).

Figure 3. Kinetics of precipitation of potassium bicarbonate suspension. Norma DEA,\%:1-57, 2-100, 3133, 4-147.

Figure 4 Change the degree of deposition depending on the rate of DEA. Isochranes, sec: 1-30, 2-60, 3-120, 4-240, 5-300.

Figure 5. Thermogram of potassium bicarbonate sample No. 8 tab. 2

Figure 6 Radiograph of the product of potassium bicarbonate obtained under the conditions of the experience 8 tab. 2 .

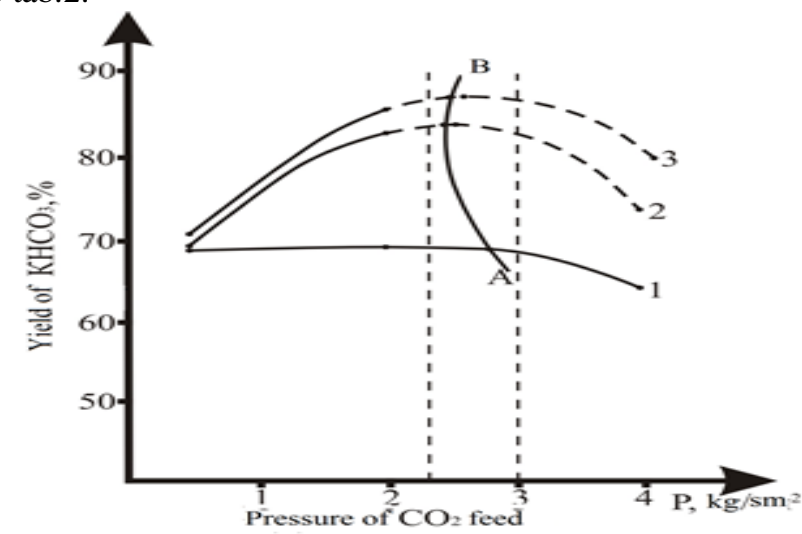

Figure 1. The change in the degree of yield of potassium bicarbonate depending on the pressure of carbon dioxide and the norm of DEA. Norm DEA, \%: 1 100, 2-133, 3-147.
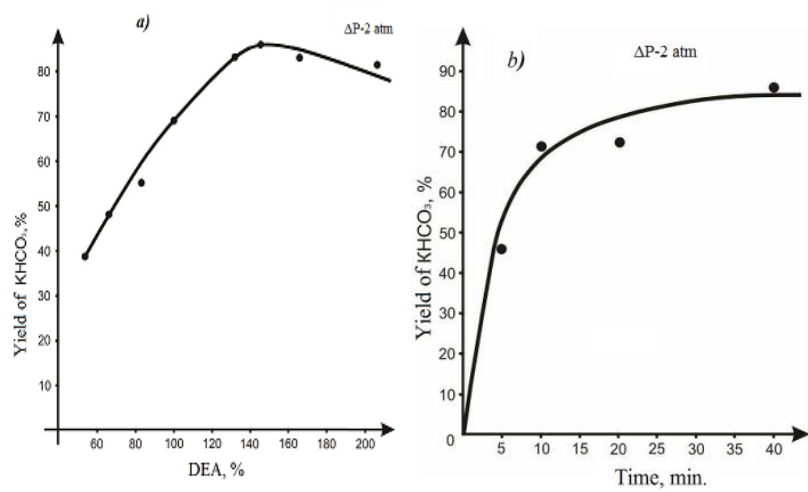

Figure $2(a, b)$. Change in the degree of potassium bicarbonate yield depending on the carbon dioxide pressure (a) and the process duration (b). 


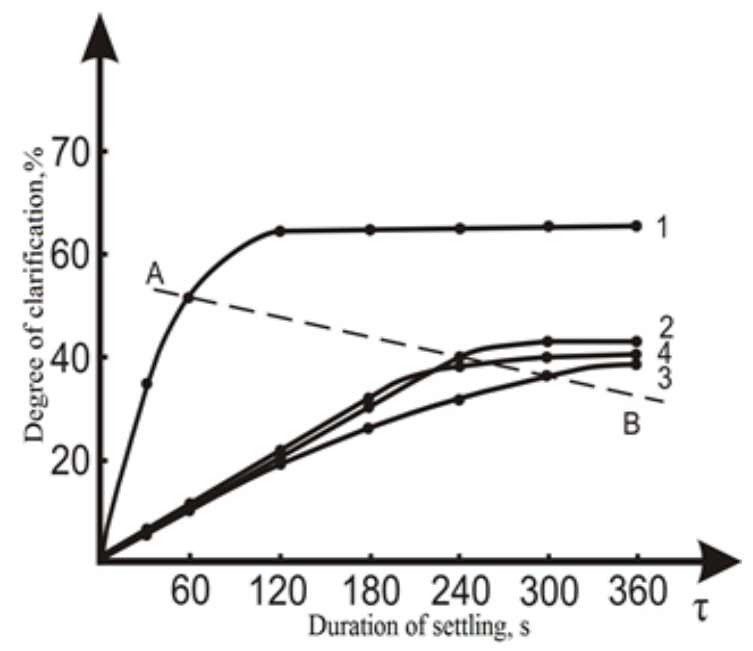

Figure 3. Kinetics of precipitation of potassium bicarbonate suspension. Norma DEA, \%:1-57, 2-100, 3133, 4-147.

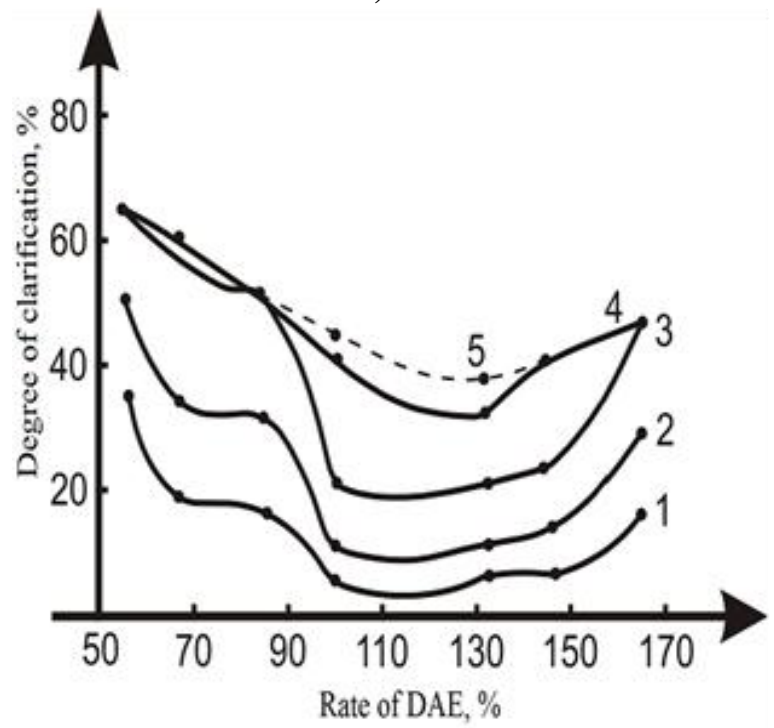

Figure 4. Change the degree of deposition depending on the rate of DEA. Isochranes, sec: 1-30, 2-60, 3-120, 4240, 5-300.

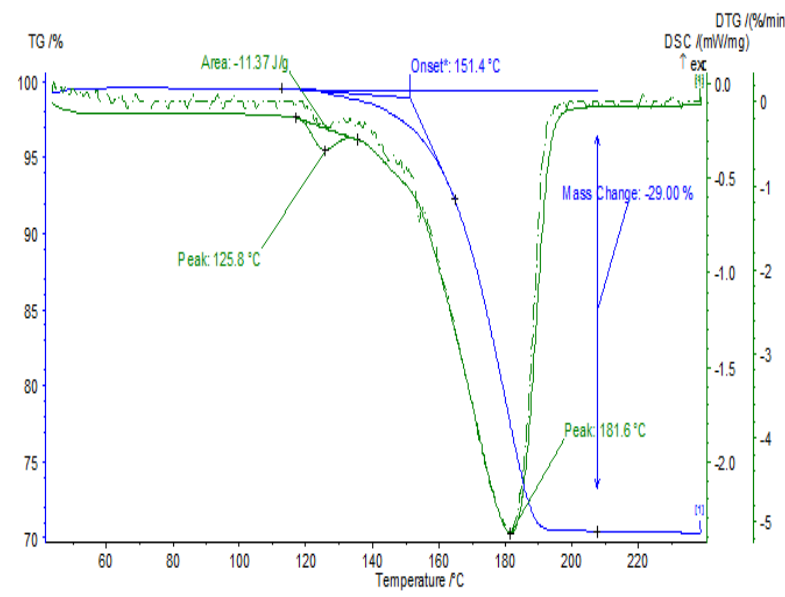

Figure 5. Thermogram of potassium bicarbonate sample No. 8 tab. 2

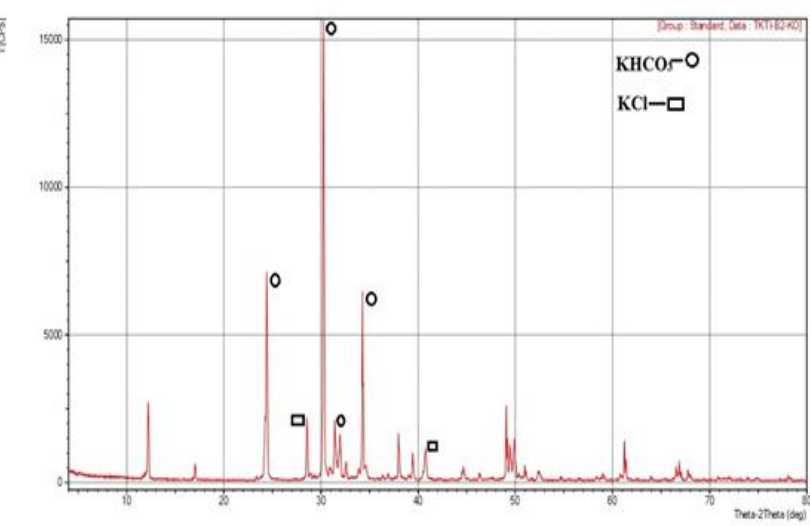

Figure 6. Radiograph of the product of potassium bicarbonate obtained under the conditions of the experience 8 tab.2.

Table 1

The influence of technological parameters on the process of carbonization of a solution of potassium chloride in the presence of DEA

\begin{tabular}{|c|c|c|c|c|c|}
\hline № & $\begin{array}{l}\text { Carbon } \\
\text { dioxide } \\
\text { supply } \\
\text { pressure } \\
\mathrm{kgf} / \mathrm{cm}^{2}\end{array}$ & $\begin{array}{c}\text { Norm } \\
\text { DEA, \% }\end{array}$ & $\begin{array}{l}\mathrm{pH} \\
\text { liquid } \\
\text { phase }\end{array}$ & $\begin{array}{l}\text { Density } \\
\text { of } \\
\text { liquid } \\
\text { phase } \\
\mathrm{g} / \mathrm{cm} 3\end{array}$ & $\begin{array}{c}\text { Yield of } \\
\mathrm{KHCO}_{3}, \\
\%\end{array}$ \\
\hline 1 & \multirow{3}{*}{0,5} & 100 & 9,04 & 1,060 & 68,9 \\
\hline 2 & & 133 & 9,14 & 1,055 & 69,48 \\
\hline 3 & & 147 & 9,21 & 1,041 & 70,92 \\
\hline 4 & \multirow{5}{*}{2,0} & 53 & 8,35 & 1,110 & 37,1 \\
\hline 5 & & 67 & 8,40 & 1,085 & 47,89 \\
\hline 6 & & 100 & 9,14 & 1,055 & 69,0 \\
\hline 7 & & 133 & 9,25 & 1,040 & 83,44 \\
\hline 8 & & 147 & 9,31 & 1,045 & 86,08 \\
\hline 9 & 4,0 & 100 & 9,26 & 1,065 & 64,46 \\
\hline
\end{tabular}

Table 2

The influence of technological parameters on the filtration rate of the suspension

\begin{tabular}{|c|c|c|c|c|c|}
\hline \multirow[t]{2}{*}{ № } & \multirow{2}{*}{$\begin{array}{c}\text { Pressure } \\
\text { carbon dioxide } \\
\text { supply } \\
\text { gas, } \\
\mathrm{kgf} / \mathrm{sm}^{2}\end{array}$} & \multirow{2}{*}{$\begin{array}{c}\text { Rate of } \\
\text { DEA } \\
\%\end{array}$} & \multirow{2}{*}{$\begin{array}{c}\mathrm{L} \cdot \mathrm{S} \\
\text { in } \\
\text { suspensions }\end{array}$} & \multicolumn{2}{|c|}{$\begin{array}{l}\text { Filtration rate, } \\
\mathrm{kg} / \mathrm{m}^{2 *} \mathrm{~h}\end{array}$} \\
\hline & & & & solid phase & liquid phase \\
\hline 1 & \multirow{3}{*}{0,5} & 100 & $4,72: 1$ & 417,28 & 1290,04 \\
\hline 2 & & 133 & $3,52: 1$ & 468,79 & 2420,30 \\
\hline 3 & & 147 & $3,64: 1$ & 850,80 & 3098,92 \\
\hline 4 & \multirow{5}{*}{2,0} & 53 & $6,67: 1$ & 355,85 & 2186,93 \\
\hline 5 & & 67 & $5,11: 1$ & 587,50 & 2435,89 \\
\hline 6 & & 100 & $3,59: 1$ & 921,97 & 2789,40 \\
\hline 7 & & 133 & $3,01: 1$ & 1143,42 & 2933,73 \\
\hline 8 & & 147 & $3,02: 1$ & 2867,17 & 7462,34 \\
\hline 9 & 4,0 & 100 & $3,81: 1$ & 897,98 & 3004,92 \\
\hline
\end{tabular}




\section{REFERENCES}

1. G.Tukhtaeva., M.Yulchiev., E. Baimuratova., A. Erkayev., A.N. Bobokulov., Development of production of potash by conversion of potassium chloride with ammonium salts.// Technical and socio-economic sciences important issues in the field Republic of Uzbekistan -1 volume, Tashkent - 2013 pages. 26-27.

2. A.U. Erkayev., Z.K.Toirov., A.N. Bobokulov. S.Azlarov., D. Bayraeva. The study of the process of obtaining potassium carbonate. // Proceedings of the 9th International Scientific Conference "Mining and Metallurgical Complex: Achievements, Problems and Modern Development Prospects" Navoi - 2016 - 433 p.

3. A.N. Bobokulov., A.U. Erkayev., Z.K.Toirov., Kucharov B.Kh. The study of the separation of potassium bicarbonate from carbonated suspensions. // Modern problems and prospects of chemistry and chemicalmetallurgical production, republican scientific and technical conference. Navoi-2018 31-32 st.

4. Wasag T. Otrzymywanie potazu metoda aminowa $\mathrm{z}$ zastosowaniem dwuetyloaminy / [T. Wasag, T. Wasag, U. Siewielec, G. Poleszczuk] // Przemysl chemiczny. 1974. - № 2. - p. 94 - 97.

5. Wasag T. Zastoswanie amin do produkcji weglanow alkalicznych / T. Wasag, T. Wasag, G. Poleszczuk // Chemik. - 1976. - Vol. 29, No. 9. - P. 293 - 297.

6. Kovilis S.S. The technique of measuring the density of liquids and solids. - M., Standard, 1969. - 70s.

7. Krasheninnikov S.A. et al. Obtaining soda and potash from the sylvinites of the Karluk field. // Him.prom-st .1984.- № 2. p.-p.93.

8. Doebelin, N., \& Kleeberg, R. (2015). Profex: a graphical user interface for the Rietveld refinement program BGMN. Journal of applied crystallography, 48 (5), 1573 1580.

9. Panzhiev O.Kh., Toirov ZK, Bozorov ON, Bobokulov A.N., Chemical Technology of Inorganic Substances // Textbook. Tashkent - 2018. - 187s.

10. A.N. Bobokulov., A.U. Erkayev., Z.K.Toirov. Study of the process of obtaining potassium bicarbonate using diethylamine. // UNIVERSUM: Chemistry and Biology, No. 10, Moscow-2017.

1. 11.A.Arkayev., A.N. Bobokulov Potassium ammonium chloride-suv systeming scoring $20,40,60$ va $800 \mathrm{C}$ dan and isothermal diagram of "agranish". // "Umidli Kimyoglarar-2015" - technics anzhumanining maholar ty̆plami -2tom, Tashkent $2015 \mathrm{nd}$. 31-32 bet

11. A.N. Bobokulov., A.U. Erkayev., Z.K.Toirov., Kucharov B.Kh. Investigation of the process of carbonization of potassium chloride solutions in the presence of diethylamine. // Modern problems and prospects of chemistry and chemical-metallurgical production, republican scientific and technical conference. Navoi2018 38-39 st. 